Article

\title{
Preparation and Characterization of Nano-Selenium Decorated by Chondroitin Sulfate Derived from Shark Cartilage and Investigation on Its Antioxidant Activity
}

\author{
Jianping Chen ${ }^{1,2, *}$, Xuehua Chen ${ }^{1}$, Jiarui Li ${ }^{1}$, Baozhen Luo ${ }^{1}$, Tugui Fan ${ }^{1}$, Rui Li ${ }^{1,2}{ }^{1}$, Xiaofei Liu ${ }^{1,2}$, \\ Bingbing Song ${ }^{1,2}$, Xuejing Jia ${ }^{1,2}$ and Saiyi Zhong ${ }^{1,2, *}$
}

1 Guangdong Provincial Key Laboratory of Aquatic Product Processing and Safety, Guangdong Provincial Engineering Technology Research Center of Seafood, Guangdong Province Engineering Laboratory for Marine Biological Products, Key Laboratory of Advanced Processing of Aquatic Product of Guangdong Higher Education Institution, Guangdong Provincial Science and Technology Innovation Center for Subtropical Fruit and Vegetable Processing, College of Food Science and Technology, Guangdong Ocean University, Zhanjiang 524088, China; 18977740415@163.com (X.C.); rain8413@163.com (J.L.); 13413650541@163.com (B.L.); ftg2693982106@163.com (T.F.); liruihn@163.com (R.L.); liuxf169@126.com (X.L.); 15891793858@163.com (B.S.); jiaxj@gdou.edu.cn (X.J.)

2 Collaborative Innovation Center of Seafood Deep Processing, Dalian Polytechnic University, Dalian 116034, China

* Correspondence: cjp516555989@gdou.edu.cn (J.C.); zsylxc@126.com (S.Z.); Tel.: +86-187-1915-6629 (J.C.); +86-188-2669-9336 (S.Z.)

Citation: Chen, J.; Chen, X.; Li, J.; Luo, B.; Fan, T.; Li, R.; Liu, X.; Song, B.; Jia, X.; Zhong, S. Preparation and Characterization of Nano-Selenium Decorated by Chondroitin Sulfate Derived from Shark Cartilage and Investigation on Its Antioxidant Activity. Mar. Drugs 2022, 20, 172. https://doi.org/10.3390/ md20030172

Academic Editors: Donatella Degl'Innocenti and Marzia Vasarri

Received: 3 February 2022

Accepted: 24 February 2022

Published: 26 February 2022

Publisher's Note: MDPI stays neutral with regard to jurisdictional claims in published maps and institutional affiliations.

Copyright: (C) 2022 by the authors. Licensee MDPI, Basel, Switzerland. This article is an open access article distributed under the terms and conditions of the Creative Commons Attribution (CC BY) license (https:// creativecommons.org/licenses/by/ $4.0 /)$.

\begin{abstract}
In the present study, a selenium-chondroitin sulfate (SeCS) was synthesized by the sodium selenite $\left(\mathrm{Na}_{2} \mathrm{SeO}_{3}\right)$ and ascorbic acid $(\mathrm{Vc})$ redox reaction using chondroitin sulfate derived from shark cartilage as a template, and characterized by SEM, SEM-EDS, FTIR and XRD. Meanwhile, its stability was investigated at different conditions of $\mathrm{pH}$ and temperatures. Besides, its antioxidant activity was further determined by the DPPH and ABTS assays. The results showed the SeCS with the smallest particle size of $131.3 \pm 4.4 \mathrm{~nm}$ and selenium content of $33.18 \%$ was obtained under the optimal condition (CS concentration of $0.1 \mathrm{mg} / \mathrm{mL}$, mass ratio of $\mathrm{Na}_{2} \mathrm{SeO}_{3}$ to $\mathrm{Vc}$ of $1: 8$, the reaction time of $3 \mathrm{~h}$, and the reaction temperature of $25^{\circ} \mathrm{C}$ ). SEM image showed the SeCS was an individual and spherical nanostructure and its structure was evidenced by FTIR and XRD. Meanwhile, SeCS remained stable at an alkaline $\mathrm{pH}$ and possessed good storage stability at $4{ }^{\circ} \mathrm{C}$ for 28 days. The results on scavenging free radical levels showed that SeCS exhibited significantly higher antioxidant activity than SeNPs and CS, indicating that SeCS had a potential antioxidant effect.
\end{abstract}

Keywords: nanoselenium; chondroitin sulfate derived from shark cartilage; structure characterization; antioxidant activity

\section{Introduction}

Reactive oxygen species (ROS) are the result of the normal cell metabolism of living organisms. However, when the production of ROS exceeds the scavenging capacity of living organisms, oxidative stress occurs [1]. Excessive reactive oxygen species (ROS) not only affect normal metabolism, but also is closely related to the occurrence and development of various diseases, including cardiovascular diseases [2], Alzheimer's disease [3], nonalcoholic fatty liver disease [4], and so on. As an essential micronutrient for human health, selenium (Se) plays a vital role in protecting against oxidative stress [5]. Nevertheless, the beneficial and harmful doses of Se is an extremely narrow margin, which limits its practical applications in food and medicine [6]. Therefore, it is necessary to take effective measures to solve this problem.

Nanotechnology, as a technology developed in recent years, has been widely used in the field of biology. Selenium nanoparticles (SeNPs) have been widely used as drug 
carriers due to their advantages of small volume, large specific surface area, and unique physical and chemical properties. Previous studies have found that SeNPs can remove harmful peroxides from the body through glutathione peroxidase (GSH-PX) and protect the membrane structure of the body from damage [7]. Meanwhile, compared with organic and inorganic selenium compounds [8], SeNPs possesses higher bioactivity like antioxidant activity, better bioavailability and lower toxicity [9]. However, SeNPs are very unstable in the liquid phase and tend to aggregate and form gray or black selenium with a large particle size, thus losing the bioavailability and bioactivity of SeNPs [10]. Therefore, a suitable stabilizer is needed to improve its stability.

Natural bioactive polysaccharides have attracted more and more attention because they are rich in hydrophilic groups, such as hydroxyls, and are considered as ideal templates for SeNPs stabilization. A variety of polysaccharides have been reported to modify SeNPs and the modified SeNPs have been found to have strong antioxidant activity $[6,11,12]$. Chondroitin sulfate (CS), a natural anionic glycoaminoglycan, is extracted from various marine animal cartilages, such as shark, skate and so on $[13,14]$. Studies showed CS exhibited a variety of biological activities, such as antioxidant activity [15], anti-inflammatory activity [16] and anti-tumor activity [17]. Since it is rich in carboxyl and hydroxyl groups, it is often used to stabilize SeNPs. For example, Han et al. reported the preparation method of selenium-chondroitin sulfate (SeCS) using CS as a stabilizer to stable SeNPs, but the Se content in SeCS is only 10.1\%, and the study on its stability has not been reported [18]. Since the Se content and stability of SeCS are related to its biological activity, it is necessary to further improve the Se content and investigate the stability of SeCS. Therefore, in this study, we screened the preparation conditions of SeCS, investigated its stability at a different $\mathrm{pH}$ and temperature, and evaluated its antioxidant activity using 2,2diphenyl-1-picrylhydrazyl (DPPH) and 2,2'-azino-bis (3-ethylbenzo-thiazoline-6-sulfonic acid) diammonium salt (ABTS) assays. This study provides a theoretical basis for the application of SeCS as a fresh antioxidant agent in food and medicine.

\section{Results and Discussion}

\subsection{Determination of Preparation Conditions of SeCS}

\subsubsection{Determination of CS Concentration}

In order to evaluate the effect of CS concentration on the formation of SeCS, the particle sizes of SeCS prepared with different concentrations of CS were measured by nanoparticle size analyzer. As shown in Figure 1A, the particle sizes of SeNPs with $0.05 \mathrm{mg} / \mathrm{mL}$ CS surface decoration were $278.70 \pm 9.47 \mathrm{~nm}$. The average particle diameters of SeNPs were significantly decreased to $113.7 \pm 2.89 \mathrm{~nm}$ in the presence of $0.1 \mathrm{mg} / \mathrm{mL} \mathrm{CS}$, indicating that CS between $0.05 \mathrm{mg} / \mathrm{mL}$ and $0.1 \mathrm{mg} / \mathrm{mL}$ could inhibit the aggregation of SeNPs with the increase of CS concentration. The result was in accordance with the previous study, which demonstrated that the particle diameters of SeNPs decorated with $1.0 \mathrm{mg} / \mathrm{mL}$ chitosan were smaller than that synthesized with $0.6 \mathrm{mg} / \mathrm{mL}$ chitosan [19]. However, when CS concentration is greater than $0.1 \mathrm{mg} / \mathrm{mL}$, the particle size of SeCS in the system became larger. This might be because CS molecules aggregated to reduce its hydrophilic groups ${ }^{\prime}$ function, resulting in the particle size become larger. Therefore, the optimal concentration of CS was selected as $0.1 \mathrm{mg} / \mathrm{mL}$.

\subsubsection{Determination of Molar Ratio of $\mathrm{Na}_{2} \mathrm{SeO}_{3}$ to $\mathrm{Vc}$}

According to the reaction equation, sodium selenite $\left(\mathrm{Na}_{2} \mathrm{SeO}_{3}\right)$ reacts with ascorbic acid $(\mathrm{Vc})$ at the coefficient of 1:2. However, in fact, an excess of $\mathrm{V}_{\mathrm{C}}$ needs to be added to the system to prevent SeNPs from being oxidized. Therefore, in this study, fixing the CS concentration of $0.1 \mathrm{mg} / \mathrm{mL}$, the reaction time of $3 \mathrm{~h}$ and the reaction temperature of $55^{\circ} \mathrm{C}$, the molar ratio of $\mathrm{Na}_{2} \mathrm{SeO}_{3}$ to $\mathrm{Vc}$ varied from 1:2 to 1:10. The particle sizes of SeCS prepared with different molar ratios of $\mathrm{Na}_{2} \mathrm{SeO}_{3}$ to $\mathrm{V}_{\mathrm{c}}$ were shown in Figure 1B. The results showed that the average particle diameters of $\mathrm{SeCS}$ obtained with the molar ratio of $\mathrm{Na}_{2} \mathrm{SeO}_{3}$ to Vc of 1:2 were $187.3 \pm 12.48 \mathrm{~nm}$. As the molar ratio of $\mathrm{Na}_{2} \mathrm{SeO}_{3}$ to $\mathrm{Vc}_{\mathrm{c}}$ increased to 1:8, 
the particle size reached the smallest. It was speculated that excessive Vc could improve the growth of the crystal nucleus to stabilize SeCS [20]. However, further increasing Vc concentration meant the particle size became larger due to the unstable reaction system. So, it might be the reason why the diameter of the SeCS prepared with a molar ratio of $\mathrm{Na}_{2} \mathrm{SeO}_{3}$ to $\mathrm{Vc}$ of 1:10 was larger than that obtained with a molar ratio of $\mathrm{Na}_{2} \mathrm{SeO}_{3}$ to $\mathrm{Vc}$ of 1:8. Therefore, the optimal molar ratio of $\mathrm{Na}_{2} \mathrm{SeO}_{3}$ to $\mathrm{Vc}$ was selected as 1:8.

A

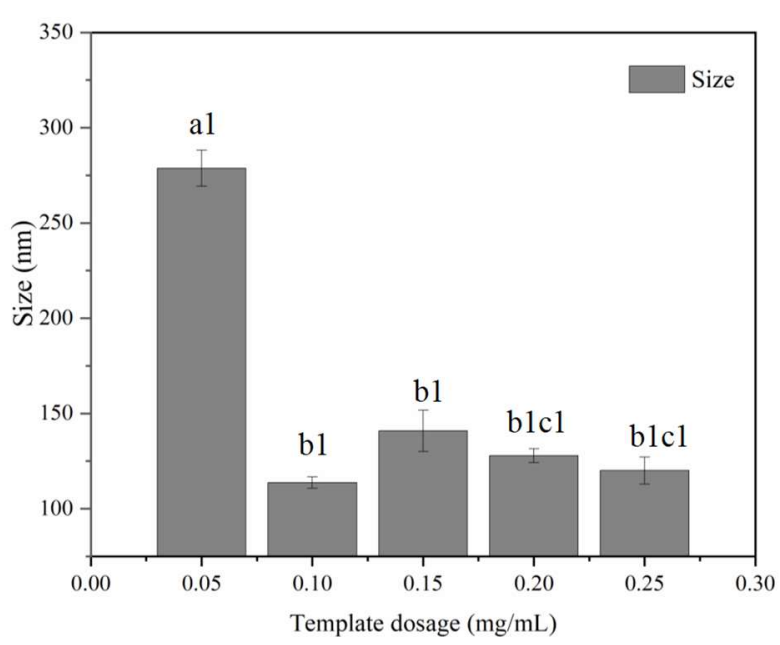

$\mathrm{C}$

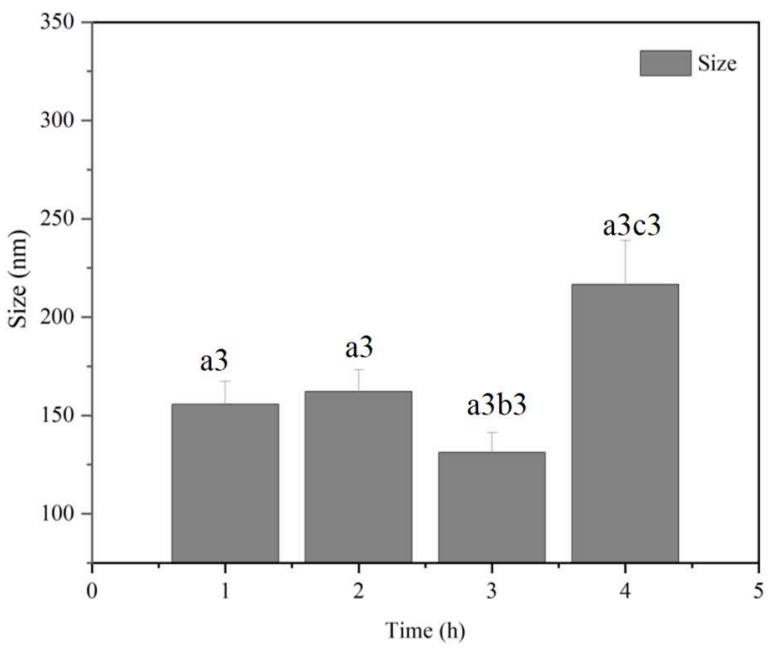

B

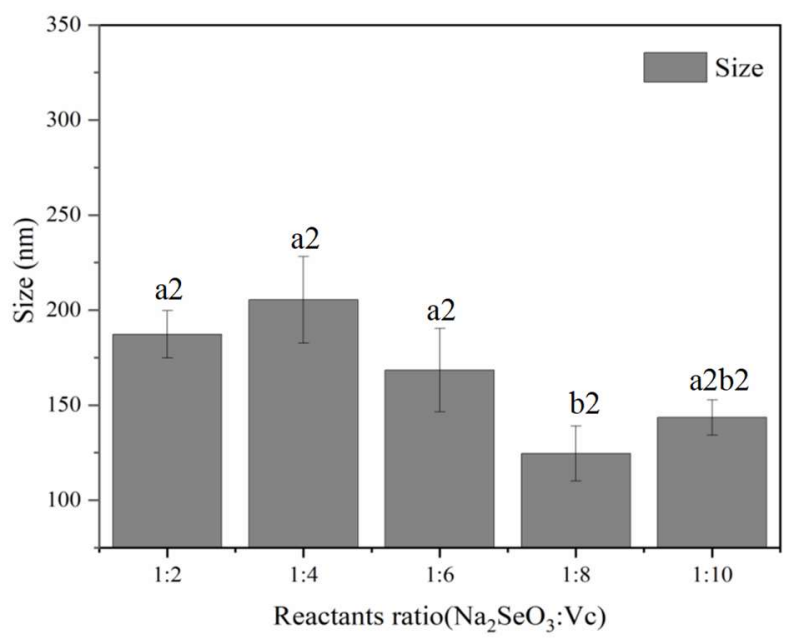

$\mathrm{D}$

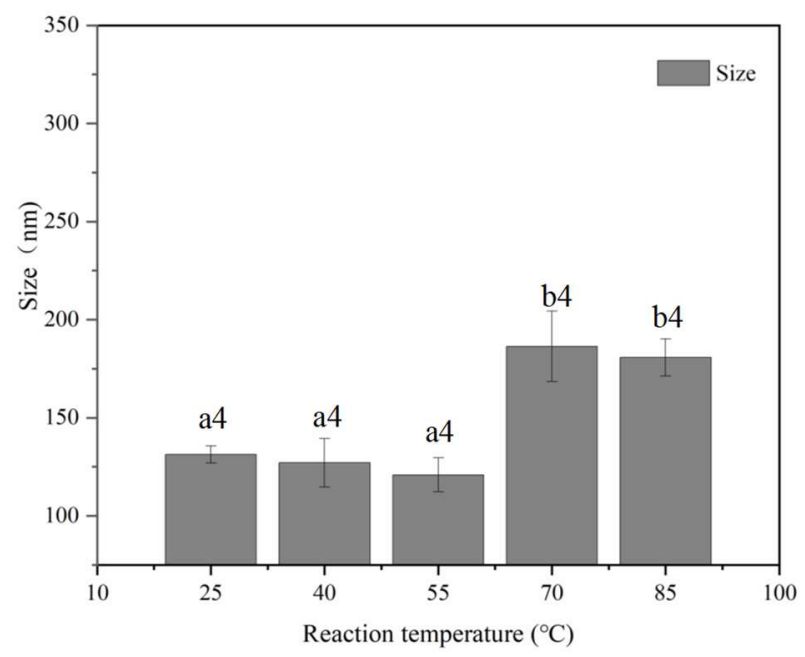

Figure 1. Effects of different template dosage (A), reactants ratio $(\mathbf{B})$, reaction time $(\mathbf{C})$, and reaction temperatures (D) on particle size of SeCS. Bars with a1, b1 and c1 represented a statistical difference $(p<0.05)$ among different template dosages. Bars with $\mathrm{a} 2$ and $\mathrm{b} 2$ represented a statistical difference $(p<0.05)$ among different reactants ratios. Bars with a3, b3 and c3 represented a statistical difference $(p<0.05)$ among different times. Bars with a 4 and $\mathrm{b} 4$ represented a statistical difference $(p<0.05)$ among different reaction temperatures.

\subsubsection{Determination of Reaction Time}

Studies showed that reaction time had a vital role to regulate the SeNPs reaction system [21]. If the reaction time is too short, the reaction between $\mathrm{Na}_{2} \mathrm{SeO}_{3}$ and $\mathrm{Vc}$ is not sufficient. However, if the reaction time is too long, the SeNPs in the system will gather, leading to increasing the particle size. Therefore, we next further investigated the influence of reaction time on the particle size of system. Fixing the CS concentration of $0.1 \mathrm{mg} / \mathrm{mL}$, the molar mass ratio of $\mathrm{Na}_{2} \mathrm{SeO}_{3}$ to $\mathrm{Vc}$ of $1: 8$ and the reaction temperature of $55^{\circ} \mathrm{C}$, the reaction time varied from $1 \mathrm{~h}$ to $4 \mathrm{~h}$. The result was shown in Figure 1C. When the reaction 
time extended from $1 \mathrm{~h}$ to $2 \mathrm{~h}$, no significant difference was observed in the particle size of the obtained SeCS. When the reaction time increased to $3 \mathrm{~h}$, the particle size of the obtained SeCS reached to $131.2 \pm 9.97 \mathrm{~nm}$. When the reaction time exceeded $3 \mathrm{~h}$, the particle size of the obtained SeCS remarkably increased. Therefore, we selected the reaction time of $3 \mathrm{~h}$ as the optimal reaction time to prepare SeCS.

\subsubsection{Determination of Reaction Temperature}

Fixing the CS concentration of $0.1 \mathrm{mg} / \mathrm{mL}$, the molar mass ratio of $\mathrm{Na}_{2} \mathrm{SeO}_{3}$ to $\mathrm{Vc}$ of $1: 8$, reaction time of $3 \mathrm{~h}$, the reaction temperature varied from 25 to $85^{\circ} \mathrm{C}$. The particle size of the obtained SeCS is shown in Figure 1D. It could be seen that although the particle size of the obtained SeCS slightly decreased at $55^{\circ} \mathrm{C}$, there was no significant difference between $25^{\circ} \mathrm{C}$ and $55^{\circ} \mathrm{C}$. When the reaction temperature was further separately increased to $70{ }^{\circ} \mathrm{C}$ and $85^{\circ} \mathrm{C}$, the particle size of the obtained SeCS both significantly increased. The reason might be that heating easily led to the violent movement of nanoparticles, thus increasing the chance and intensity of collisions and intensifying aggregation [22]. Therefore, in terms of saving energy, the optimal reaction temperature was selected as $25^{\circ} \mathrm{C}$.

In summary, these above results demonstrated that we optimized conditions for preparing SeCS as a CS concentration of $0.1 \mathrm{mg} / \mathrm{mL}$, the molar mass ratio of $\mathrm{Na}_{2} \mathrm{SeO}_{3}$ to $\mathrm{Vc}_{\mathrm{c}}$ of $1: 8$, reaction time of $3 \mathrm{~h}$ and reaction temperature of $25^{\circ} \mathrm{C}$, so SeCS used in subsequent experiments were obtained in optimal reaction conditions. Under the optimal reaction conditions, the SeCS was successfully prepared and inductively coupled plasma mass spectrometry (ICP-MS) was used to measure the Se content of the SeCS obtained. It was found that the Se content in SeCS was 33.18\%, which is higher than that reported in previous studies $[18,23]$.

\subsection{Characterization of SeCS}

\subsubsection{Scanning Electron Microscopy (SEM)}

In order to verify the above results, SEM was used to analyze the morphology of SeNPs and SeCS. As shown in Figure 2, the SEM results of SeNPs clearly revealed that SeNPs without CS surface decoration showed serious aggregation and formed large particles chunks (Figure 2A,C). Nevertheless, the addition of CS accelerated the production of homogeneous spherical SeCS with high dispersibility (Figure 2B,D), which further confirmed the formation of SeCS.
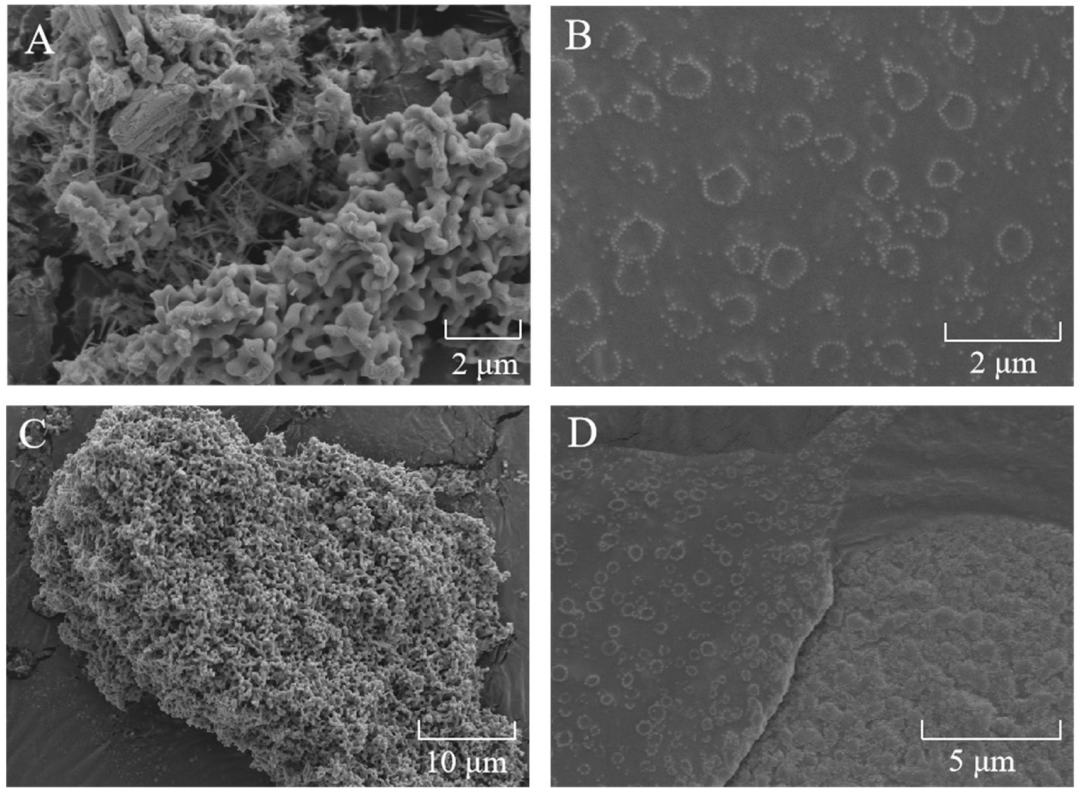

Figure 2. SEM images of SeNPs $(\mathbf{A}, \mathbf{C})$ and SeCS $(\mathbf{B}, \mathbf{D})$ powders. The SeNPs were obtained in the same procedure of SeCS without CS. 


\subsubsection{Element Analysis of SeCS}

To determine chemical compositions of SeCS samples, scanning electron microscopy equipped with an energy dispersion spectrum detector (SEM-EDS) was employed. The results were shown in Figure 3. It was found that C (44.16\%), O (37.74\%), and $\mathrm{Na}(18.1 \%)$ were the chemical compositions of CS (Figure 3A). Furthermore, an SEM-EDS investigation of SeNPs showed the percentages of Se, $\mathrm{C}$ and $\mathrm{O}$ atoms were $92.27 \%, 7.43 \%$ and $0.30 \%$ (Figure 3B), which were similar to previous findings of Ye et al. [21]. An EDS investigation of SeCS (Figure 3C) showed that the presence of a strong Se atoms signal $(65.73 \%)$. The existence of the $\mathrm{Na}$ atom $(1.27 \%), \mathrm{C}$ atom $(25.55 \%)$ and $\mathrm{O}$ atom $(7.44 \%)$ in SeCS suggested that CS successfully combined to the surface of the SeNPs.
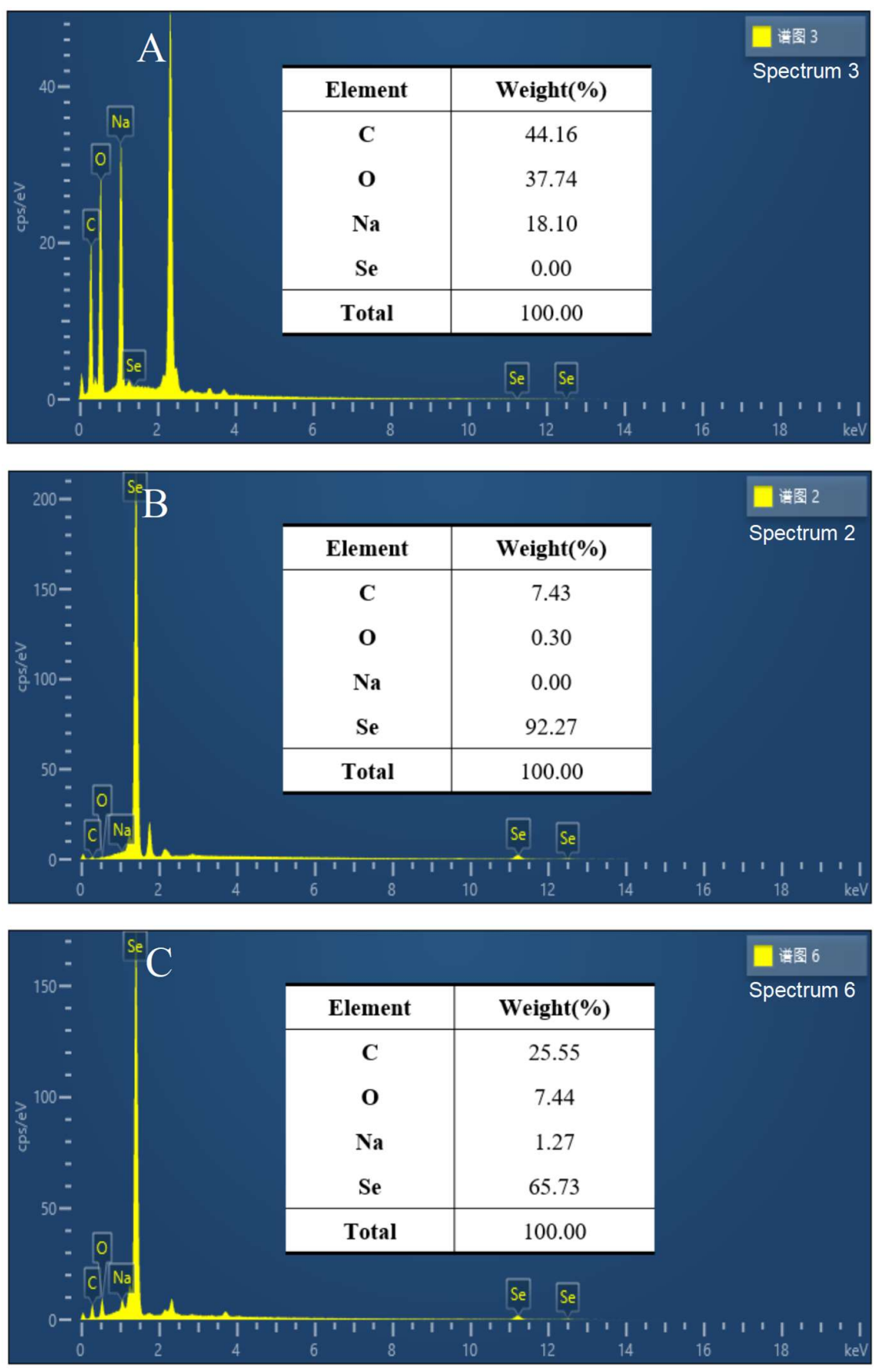

Figure 3. SEM-EDS element analysis of CS (A), SeNPs (B) and SeCS (C). The SeNPs were obtained in the same procedure of $\mathrm{SeCS}$ without CS. 


\subsubsection{Fourier Transform Infrared Spectroscopy (FT-IR) Analysis}

To confirm the chemical binding of CS to the surface of the SeNPs, FTIR spectroscopy is used to ascertain the formation of SeCS. The FTIR spectra of CS and SeCS were shown in Figure 4. The typical IR spectrum of CS was presented in Figure 4 which was in good agreement with the literature [23]. The FTIR spectrum of CS exhibited an absorption band at $3402 \mathrm{~cm}^{-1}$, indicating the overlapping of $-\mathrm{OH}$ and $-\mathrm{NH}$ stretching vibrations. Additionally, the absorption peaks of CS were $1070 \mathrm{~cm}^{-1}$ and $1128 \mathrm{~cm}^{-1}, 1224 \mathrm{~cm}^{-1}, 1419 \mathrm{~cm}^{-1}$, and $1635 \mathrm{~cm}^{-1}$, which corresponded to the characteristic asymmetric stretching vibrations of the $\mathrm{C}-\mathrm{O}-\mathrm{C}$ bridge ( $\beta-1,4$ glycosidic bonds), asymmetric stretching vibrations of $-\mathrm{S}=\mathrm{O}$, stretching vibrations of the $-\mathrm{COOH}$ and stretching vibrations of the $-\mathrm{C}=\mathrm{O}$ of $-\mathrm{NHCO}-$. By comparing the FTIR spectra of CS, SeCS resembled that of CS and there were no new absorption peaks in the FTIR spectrum of SeCS, indicating that the reaction between CS and SeNPs did not generate any new covalent bonds. However, an obvious change occurred in the peak locations of SeCS, indicating that the main interaction between CS and SeNPs was physical adsorption.

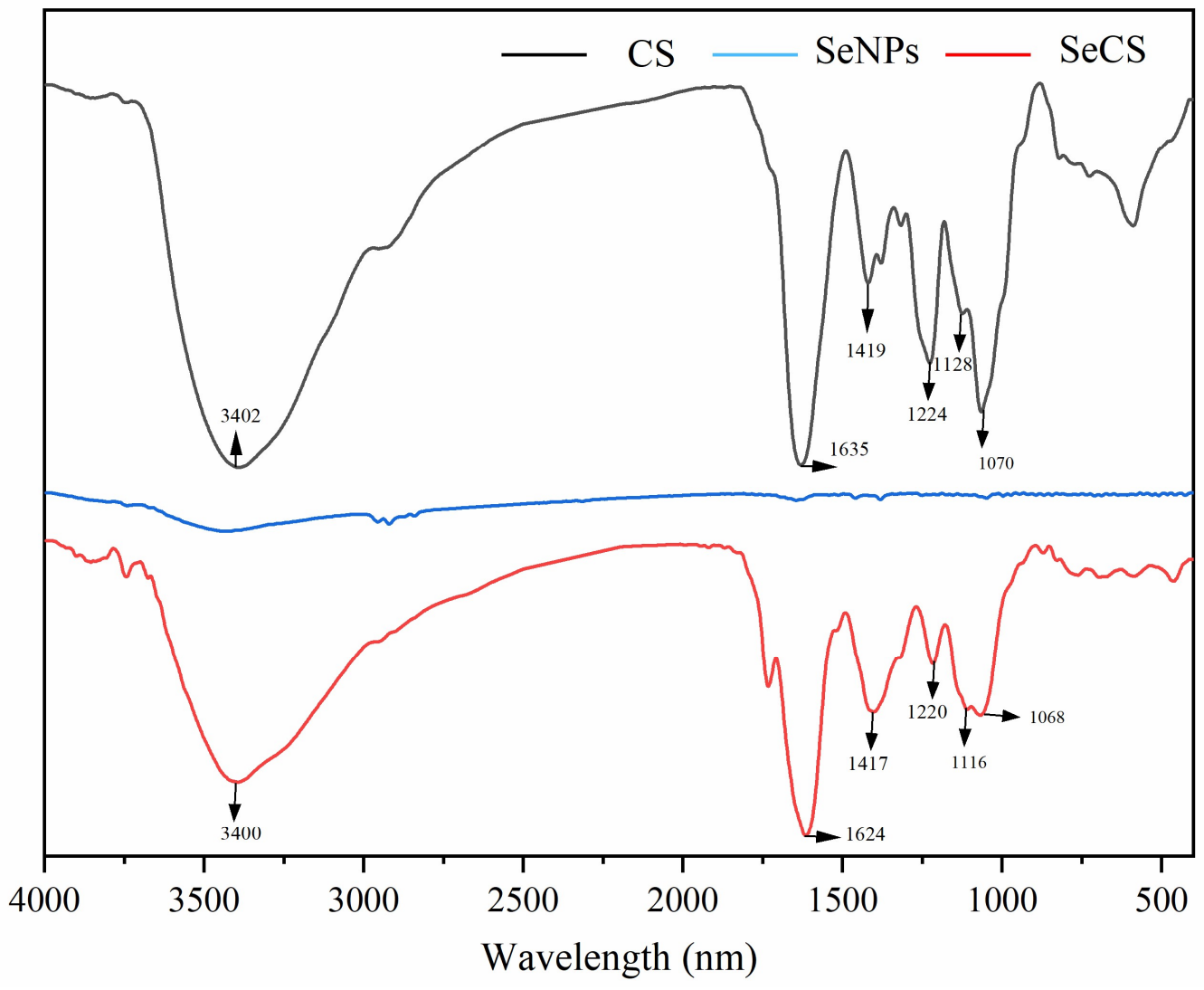

Figure 4. FT-IR spectra of CS, SeNPs and SeCS. The SeNPs were obtained in the same procedure of SeCS without CS.

\subsubsection{Powder X-ray Diffractometry (XRD) Analysis}

On this basis of FT-IR analysis, XRD was used to characterize the formation of SeCS. XRD analysis could detect phase identification of crystalline materials. The intensity and sharpness of XRD peaks reflected the crystalline nature of the sample. The XRD spectra of CS, SeNPs and SeCS were shown in Figure 5. As shown in Figure 5, the X-ray diffractogram of SeNPs showed two broad peaks in the ranges of $20-40^{\circ}$ and $40-60^{\circ}(2 \theta)$, indicating that SeNPs existed in an amorphous form. This result was in good agreement with the literature [21]. No sharp peaks were found in the XRD pattern of CS and SeCS, confirming their amorphous characteristic in nature. Compared with the XRD diffraction patterns of 
CS and SeNPs, both the peak positions and intensity of SeCS shifted, suggesting that the formation of SeCS.

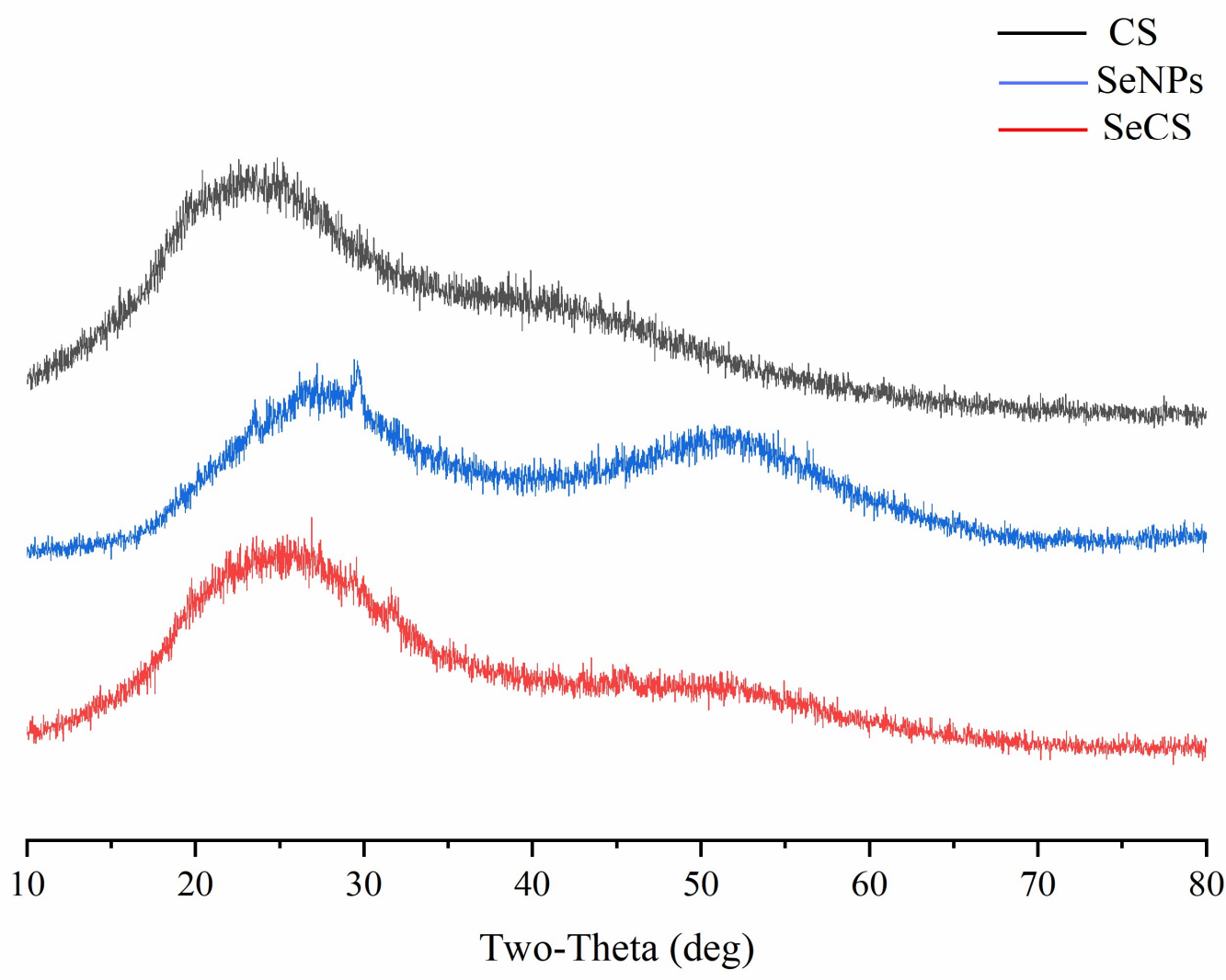

Figure 5. XRD patterns of CS, SeNPs and SeCS. The SeNPs were obtained in the same procedure of SeCS without CS.

\subsubsection{Stability of SeCS}

The stability of nanoparticles is one of the key factors for their biological function. Studies have shown that the stability of nanoparticles is closely related to $\mathrm{pH}$, storage temperature and storage time in the application medium [24,25]. Therefore, we next investigated the influence of different $\mathrm{pHs}$ and storage temperatures on the stability of SeCS. The influence of $\mathrm{pH}$ on the stability of SeCS was shown in Figure 6A. The particle diameters of SeCS notably decreased to approximately $98.9 \pm 5.9 \mathrm{~nm}$ at the $2-8 \mathrm{pH}$ range. Then, no significant shift occurred at the $8-12 \mathrm{pH}$ range. This was probably attributed to the strongest electrostatic interaction between anionic CS and SeNPs at pH 8.0 due to the sensitivity of $\mathrm{CS}$ at a low $\mathrm{pH}$ [26]. The effect of storage temperature on the stability of SeCS was shown in Figure 6B. When the SeCS solution was stored at $4{ }^{\circ} \mathrm{C}$ for 28 days, the particle size showed no obvious change. Yet, the particle diameter of the SeCS solution stored at $25^{\circ} \mathrm{C}$ for 28 days significantly increased to $262.7 \pm 13.6 \mathrm{~nm}$. It was speculated that an increase in particle diameter might be related with the changes of the internal structure of the SeCS because the increasing temperature resulted in a change in the amorphous state of SeCS to the crystalline state. Moreover, our results were consistent with previous studies that high temperature was not conducive to the stability of selenium nanoparticles $[10,26]$. These results indicated that SeCS exerted excellent stability under a refrigerating temperature and alkaline environment. 
A

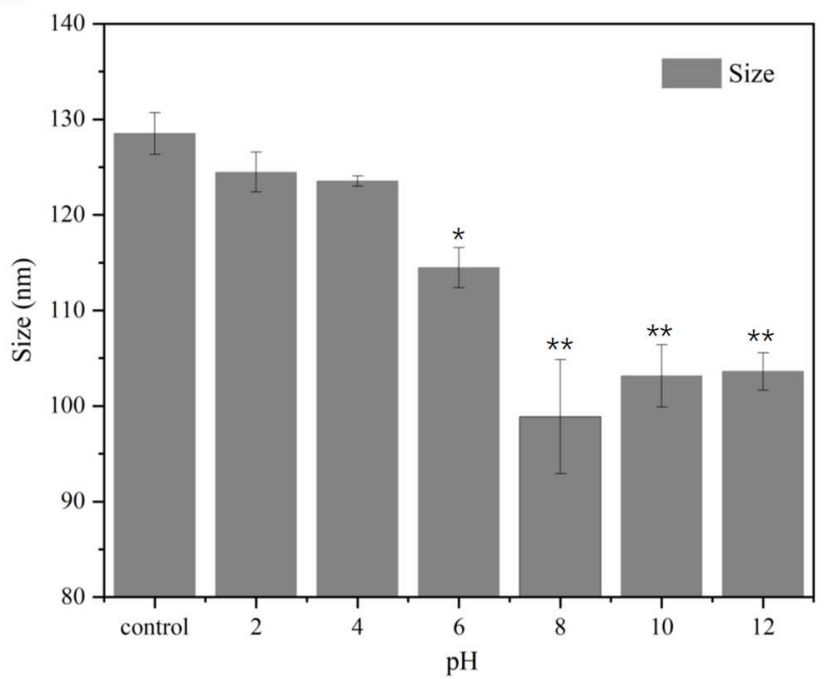

B

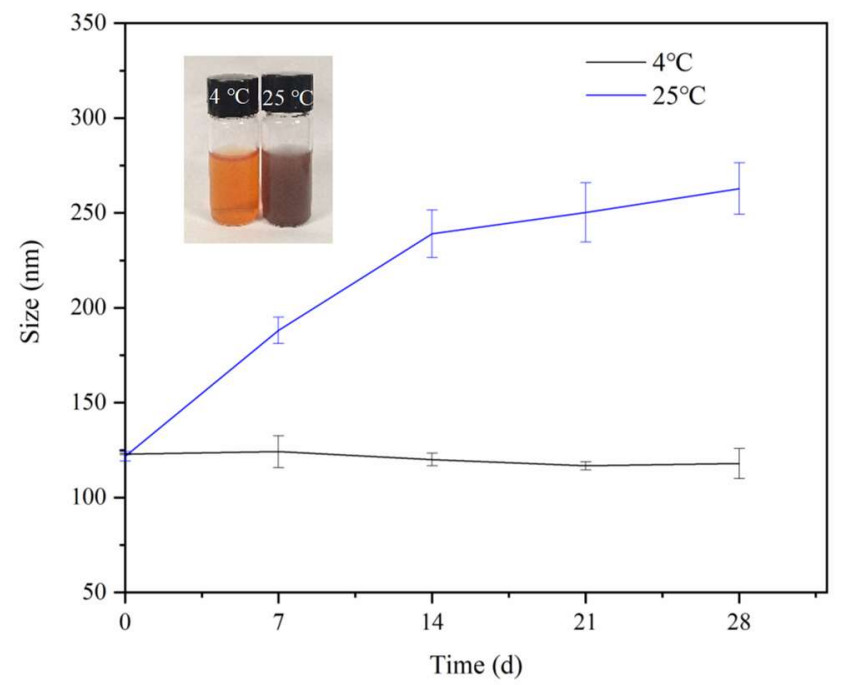

Figure 6. Effects of different $\mathrm{pHs}(\mathbf{A})$ and storage temperatures $(\mathbf{B})$ on the size of SeCS. The initial $\mathrm{pH}$ value of the control group was 6.8. $p<0.05\left(^{*}\right)$ or $\left.p<0.01{ }^{* *}\right)$ means that columns between control group and other groups are significantly different.

\subsection{The Antioxidant Property of SeCS}

The antioxidant potential of SeCS was analyzed using the DPPH assay and ABTS assay in which ascorbic acid was used as a standard. As shown in Figure 7, the DPPH and ABTS radical scavenging rates of $C S$ and SeNPs were extremely low. However, comparing with CS and SeNPs, the DPPH and ABTS radical scavenging rates of SeCS significantly increased. With the concentration of SeCS increased, the DPPH and ABTS radical scavenging rates of SeCS increased from $29.13 \pm 3.28 \%(0.1 \mathrm{mg} / \mathrm{mL})$ and $13.92 \pm 2.57 \%(20 \mu \mathrm{g} / \mathrm{mL})$ to $66.69 \pm 2.71 \%(0.5 \mathrm{mg} / \mathrm{mL})$ and $52.44 \pm 2.29 \%(100 \mu \mathrm{g} / \mathrm{mL})$, respectively. Our results indicated that SeCS could effectively scavenge the DPPH and ABTS free radical in a dosedependent manner. However, the DPPH and ABTS scavenging activities of SeCS were lower than the $\mathrm{V}_{\mathrm{C}}$, particularly in the ABTS scavenging assay.

A

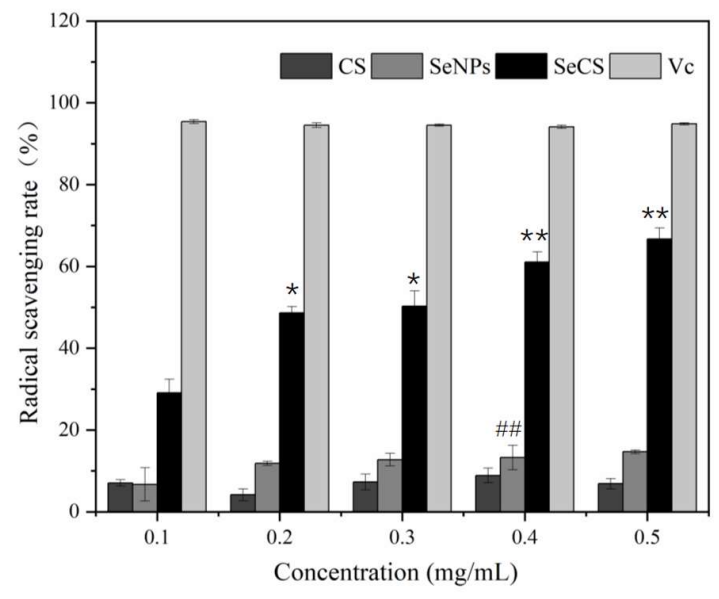

B

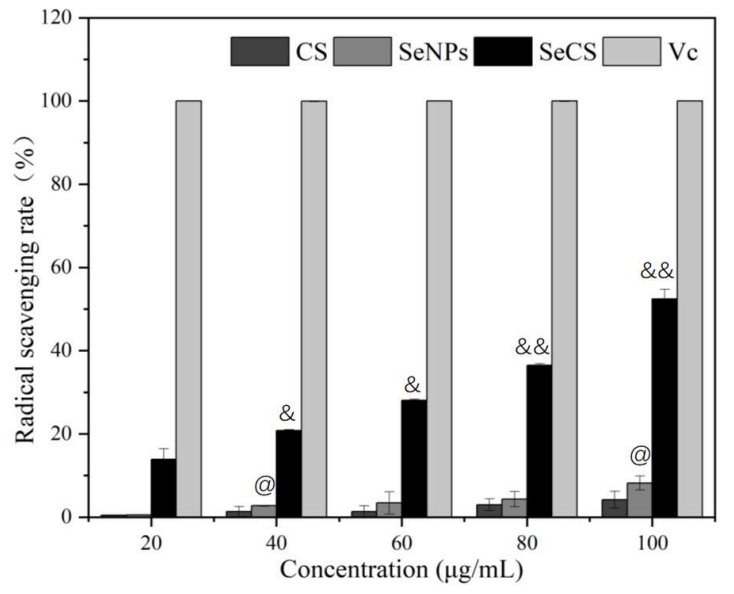

Figure 7. DPPH radical scavenging rate (A) and ABTS radical scavenging rate (B) of SeCS. $p<0.05\left(^{*}\right)$ or $\left.p<0.01{ }^{* *}\right)$ means that columns between SeCS at $0.1 \mathrm{mg} / \mathrm{mL}$ and SeCS at other concentrations are significantly different. $p<0.01$ (\#\#) means that columns between SeNPs at $0.1 \mathrm{mg} / \mathrm{mL}$ and SeNPs at $0.4 \mathrm{mg} / \mathrm{mL}$ are significantly different. $p<0.05$ (\&) or $p<0.01$ (\&\&) means that columns between SeCS at $20 \mu \mathrm{g} / \mathrm{mL}$ and SeCS at other concentrations are significantly different. $p<0.05$ (@) means that columns between SeNPs at $20 \mu \mathrm{g} / \mathrm{mL}$ and SeNPs at other concentrations are significantly different. 


\section{Materials and Methods}

\subsection{Materials}

Chondroitin sulfate (CS) derived from shark cartilage (95\% purity, Mw $=499.37$, C107703) was purchased from Aladdin. CS is composed of chondroitin 6-sulfate and chondroitin 4-sulfate, and the proportion of chondroitin 6-sulfate and chondroitin 4-sulfate detected by high performance liquid chromatography is equal to or greater than 0.33:1. $\mathrm{Na}_{2} \mathrm{SeO}_{3}$, ascorbic acid (Vc), DPPH and ABTS were supplied by Shanghai Yuanye Biotechnology Co., Ltd. (Shanghai, China). The other chemicals and reagents were of analytical purity grade.

\subsection{Determination of Preparation Conditions of SeCS Nanoparticles}

SeCS nanoparticles were prepared according to the method as described in previous study with some modifications [23]. CS was dissolved in $30 \mathrm{~mL}$ of deionized water and the concentration of CS was $0.05,0.1,0.15,0.2$, and $0.25 \mathrm{mg} / \mathrm{mL}$. Different molar ratios of $\mathrm{Na}_{2} \mathrm{SeO}_{3}$ to $\mathrm{Vc}_{\mathrm{c}}\left(\mathrm{Na}_{2} \mathrm{SeO}_{3}: \mathrm{Vc}_{\mathrm{c}}=1: 2,1: 4,1: 6,1: 8,1: 10\right)$ were added to $\mathrm{CS}$ solution and stirred at different temperatures $\left(25^{\circ} \mathrm{C}, 40^{\circ} \mathrm{C}, 55^{\circ} \mathrm{C}, 70^{\circ} \mathrm{C}, 85^{\circ} \mathrm{C}\right)$ for different times $(1 \mathrm{~h}, 2 \mathrm{~h}, 3 \mathrm{~h}$, $4 \mathrm{~h}$ ). Then, the solution was dialyzed against double-distilled water for $48 \mathrm{~h}$ with a dialysis bag $\left(\mathrm{M}_{\mathrm{W}}=3500\right)$. The optimum preparation process of SeCS was determined by particle size analysis. The final solution was freeze-dried to preserve the bioactivity of SeCS.

\subsection{Measurement of Se Content in SeCS}

The selenium content of SeCS was measured using 7500 CX ICP-MS (Agilent, Palo Alto, CA, USA). The following measurement conditions of the instrument: incident power of $1550 \mathrm{~W}$; plasma gas flow rate at $15 \mathrm{~L} / \mathrm{min}$; carrier gas flow rate at $1.0 \mathrm{~L} / \mathrm{min}$; auxiliary gas flow rate at $1.0 \mathrm{~L} / \mathrm{min}$; helium flow rate at $4.0 \mathrm{~mL} / \mathrm{min}$; atomization chamber temperature of $2{ }^{\circ} \mathrm{C}$; sampling depth of $10.0 \mathrm{~mm}$; sampling rate at $1.0 \mathrm{~L} / \mathrm{min}$.

\subsection{Characterization of SeCS}

The surface morphologies of the samples were detected using MIRA4 SEM (Tescan, Brno, Czech). The elemental compositions of the samples were measured using a MIRAL SEM-EDS (Tescan, Brno, Czech). The FT-IR spectrums of the samples were measured using a Tensor 27 spectrometer (Bruker, Karlsruhe, Germany) from 4000 to $400 \mathrm{~cm}^{-1}$ with a $4 \mathrm{~cm}^{-1}$ resolution, i.e., $2 \mathrm{mg}$ of the sample was completely ground with the spectroscopic grade potassium bromide $(\mathrm{KBr})$ powder and a transparent tablet was used for measurement. The X-ray diffractometer of the samples was obtained using an Ultima VI diffractometer (Rigaku, Tokyo, Japan) operated at $40 \mathrm{kV}$ and $40 \mathrm{~mA}$. Moreover, the samples were investigated in the range of $10-80$ degree ( $2 \theta$ angle).

\subsection{Stability of SeCS in Different Environments}

\subsubsection{Effects of Different $\mathrm{pH}$ on the Size of SeCS Nanoparticles}

After dialysis, the system solution $\mathrm{pH}$ (6.8) was adjusted to 2, 4, 6, 8, 10 and 12 using $0.1 \mathrm{M}$ sodium hydroxide $(\mathrm{NaOH})$ or $0.1 \mathrm{M}$ hydrochloric acid $(\mathrm{HCl})$. After $10 \mathrm{~min}$, the particle size of SeCS was determined by Malvern Zeizer Nano ZS particle analyzer (Malvern, Worcestershire, UK).

\subsubsection{Effects of Different Storage Temperatures on the Size of SeCS Nanoparticles}

The SeCS solutions were stored in $4{ }^{\circ} \mathrm{C}$ and $25^{\circ} \mathrm{C}$, respectively. After $0,7,14$ and 28 days, the size of SeCS was measured by Malvern Zetasizer Nano ZS particle analyzer (Malvern, Worcestershire, UK).

\subsection{Antioxidant Activity Evaluation of SeCS \\ 3.6.1. DPPH Radical Scavenging Assay}

The antioxidant activity of SeCS was evaluated using 2,2-diphenyl-1-picrylhydrazyl (DPPH) reagent according to a previously described method with some modifications [27]. 
Different concentrations $(0.1-0.5 \mathrm{mg} / \mathrm{mL})$ of CS, SeNPs and SeCS solutions were respectively added into $0.2 \mathrm{mM}$ DPPH solution in methanol. After $30 \mathrm{~min}$ incubation in a dark place, the color change of the reaction mixture was read at $517 \mathrm{~nm}$ using a TU-1901 double beam UV-visible spectrophotometry (Persee, Beijing, China). Positive control in this assay was ascorbic acid. The formula of the DPPH scavenging rate was listed below:

$$
\text { DPPH scavenging rate }(\%)=\left[\mathrm{A}_{0}-\left(\mathrm{A}_{1}-\mathrm{A}_{2}\right)\right] / \mathrm{A}_{0} \times 100 \%
$$

In the equation, $\mathrm{A}_{0}, \mathrm{~A}_{1}$ and $\mathrm{A}_{2}$ separately represented the absorbance values of control, the samples with DPPH solution and the samples without DPPH solution.

\subsubsection{ABTS Radical Scavenging Assay}

ABTS radical scavenging activity was detected as reported in previous research with some modifications [28]. Potassium persulfate $(2.6 \mathrm{mM})$ was added into ABTS $(7.4 \mathrm{mM})$ to obtain the ABTS stock solution. Then, the solution was incubated at room temperature in dark for $12 \mathrm{~h}$. Deionized water was used to dilute the solution to prepare the ABTS working solution $(0.70 \pm 0.02$ absorbance at $734 \mathrm{~nm})$. After that, $4 \mathrm{~mL}$ ABTS working solution with $1 \mathrm{~mL}$ sample were mixed for $6 \mathrm{~min}$ in the dark. Subsequently, the absorbance of mixture was recorded at a wavelength of $734 \mathrm{~nm}$ using a TU-1901 double beam UV-Visible spectrophotometer (Persee, Beijing, China). Ascorbic acid was selected as a positive control. The formula of the ABTS scavenging rate was listed below:

$$
\text { ABTS scavenging rate }(\%)=\left(1-\mathrm{A}_{\mathrm{i}} / \mathrm{A}_{0}\right) \times 100
$$

In the equation, $A_{0}$ and $A_{i}$ separately indicated the absorbance values of the blank control and the sample.

\subsection{Statistical Analysis}

All assays were repeated three times and the values were indicated as mean \pm standard deviation (SD). Statistical analysis was done using SPSS 23.0 software and Origin 2020. The comparison between two groups was analyzed by Two-tailed Student's $t$-test. $p$ value less than 0.05 or 0.01 was considered significantly shift.

\section{Conclusions}

This study provided an effective strategy to prepare SeCS using CS as a stabilizing agent. Using the reaction system at reaction conditions of a $\mathrm{Na}_{2} \mathrm{SeO}_{3}: \mathrm{V}_{\mathrm{c}}$ ratio of $1: 8$, $0.1 \mathrm{mg} / \mathrm{mL} \mathrm{CS}$, a $3 \mathrm{~h}$ reaction time and a $25{ }^{\circ} \mathrm{C}$ reaction temperature could generate spherical SeCS nanoparticles of $131.3 \pm 4.4 \mathrm{~nm}$ in diameter with a high selenium entrapment efficiency (33.18\%). These amorphous SeNPs were suggested to interact with CS via physical adsorption, and exhibited $\mathrm{pH}$ stability $(\mathrm{pH}>8)$ and storage stability at $4{ }^{\circ} \mathrm{C}$ for 28 days. Moreover, SeCS exerted a stronger in vitro antioxidant capacity than SeNPs and CS. These results confirmed the higher stability and the improved antioxidant properties of SeNPs capped with CS compared to SeNPs. Taken together, SeCSs have the potential to further develop a dietary supplement to apply in the prevention and alleviation of oxidative stress-related diseases.

Author Contributions: J.C. and X.C. designed the experiment and wrote the paper. X.C., J.L., B.L. and T.F. performed the experiments. J.C. and X.C. analyzed the data. R.L., X.L., B.S., X.J. and S.Z. participated in experimental design and contributed regents and materials. J.C. and S.Z. coordinated the studies. All authors have read and agreed to the published version of the manuscript.

Funding: This research was funded by Key-Area Research and Development Program of Guangdong Province (grant number: 2020B1111030004), Guangdong Basic and the Applied Basic Research Foundation (grant number: 2020A1515010860 and 2021A1515012455), the Guangdong Ocean University Innovation Program (grant number: 230419100), the Nanhai Youth Scholar Project of Guangdong Ocean University (grant number: QNXZ201909), the Project of Science and Technology of Zhanjiang 
City (grant number: 2020A01034), the Scientific Research Foundation of Guangdong Ocean University (grant number: R17034), the Guangdong Province ordinary universities characteristic innovation project (grant number: 2020KTSCX051), and the Guangdong Provincial Department of Education and the Innovative Team Program of High Education of the Guangdong Province (grant number: 2021KCXTD021).

Institutional Review Board Statement: Not applicable.

Data Availability Statement: Not applicable.

Conflicts of Interest: The authors declare no conflict of interest.

\section{References}

1. Birben, E.; Sahiner, U.M.; Sackesen, C.; Erzurum, S.; Kalayci, O. Oxidative stress and antioxidant Defense. World Allergy Organ. 2012, 5, 9-19. [CrossRef] [PubMed]

2. Taleb, A.; Ahmad, K.A.; Ihsan, A.U.; Qu, J.; Lin, N.; Hezam, K.; Koju, N.; Hui, L.; Ding, Q.L. Antioxidant effects and mechanism of silymarin in oxidative stress induced cardiovascular diseases. Biomed. Pharmacother. 2018, 102, 689-698. [CrossRef] [PubMed]

3. Ionescu-Tucker, A.; Cotmana, C.W. Emerging roles of oxidative stress in brain aging and Alzheimer's disease. Neurobiol. Aging 2021, 107, 86-95. [CrossRef] [PubMed]

4. Chen, Z.; Tian, R.F.; She, Z.G.; Cai, J.J.; Li, H.L. Role of oxidative stress in the pathogenesis of nonalcoholic fatty liver disease. Free. Radic. Bio. Med. 2020, 152, 116-141. [CrossRef] [PubMed]

5. Wang, Y.Y.; Qiu, Y.; Sun, L.; Ding, Z.C.; Yan, J.K. Preparation, characterization, and antioxidant capacities of selenium nanoparticles stabilized using polysaccharide-protein complexes from Corbicula fluminea. Food Biosci. 2018, 26, 177-184. [CrossRef]

6. Liu, G.Y.; Yang, X.; Zhang, J.X.; Liang, L.; Miao, F.; Ji, T.; Ye, Z.Q.; Chu, M.; Ren, J.Y.; Xu, X. Synthesis, stability and anti-fatigue activity of selenium nanoparticles stabilized by Lycium barbarum polysaccharides. Int. J. Biol. Macromol. 2021, 179, 418-428. [CrossRef]

7. Forootanfar, H.; Adeli-Sardou, M.; Nikkhoo, M.; Mehrabani, M.; Amir-Heidari, B.; Shahverdi, A.R.; Shakibaie, M. Antioxidant and cytotoxic effect of biologically synthesized selenium nanoparticles in comparison to selenium dioxide. J. Trace Elem. Med. Bio. 2014, 28, 75-79. [CrossRef]

8. Zhang, S.Y.; Zhang, J.; Wang, H.Y.; Chen, H.Y. Synthesis of selenium nanoparticles in the presence of polysaccharides. Mater. Lett. 2004, 58, 2590-2594. [CrossRef]

9. Soumaya, M.; Shrudhi, D.K.S.; Santhiya, R.; Rajeshkumar, S.; Venkat, K.S. Selenium nanoparticles: A potent chemotherapeutic agent and an elucidation of its mechanism. Colloid. Surface. B 2018, 170, 280-292.

10. Zhang, J.L.; Teng, Z.; Yuan, Y.; Zeng, Q.Z.; Lou, Z.Y.; Lee, S.H.; Wang, Q. Development, physicochemical characterization and cytotoxicity of selenium nanoparticles stabilized by beta-lactoglobulin. Int. J. Biol. Macromol. 2018, 107, 1406-1413. [CrossRef]

11. Tang, L.; Luo, X.; Wang, M.; Wang, Z.; Guo, J.; Kong, F.; Bi, Y. Synthesis, characterization, in vitro antioxidant and hypoglycemic activities of selenium nanoparticles decorated with polysaccharides of Gracilaria lemaneiformis. Int. J. Biol. Macromol. 2021, 193, 923-932. [CrossRef] [PubMed]

12. Xiao, Y.; Huang, Q.; Zheng, Z.; Guan, H.; Liu, S. Construction of a cordyceps sinensis exopolysaccharide-conjugated selenium nanoparticles and enhancement of their antioxidant activities. Int. J. Biol. Macromol. 2017, 99, 483-491. [CrossRef]

13. Martel-Pelletier, J.; Farran, A.; Montell, E.; Vergés, J.; Pelletier, J.P. Discrepancies in composition and biological effects of different formulations of chondroitin sulfate. Molecules 2015, 20, 4277-4289. [CrossRef] [PubMed]

14. Cunha, A.L.; Oliveira, L.G.; Maia, L.F.; Oliveira, L.F.C.; Michelacci, Y.M.; Aguiar, J.A.K. Pharmaceutical grade chondroitin sulfate: Structural analysis and identification of contaminants in different commercial preparations. Carbohyd. Polym. 2015, 134, 300-308. [CrossRef]

15. Müller, A.J.; Letelier, M.E.; Galleguillos, M.A.; Molina-Berríos, A.E.; Adarmes, H.H. Comparison of the antioxidant effects of synovial fluid from equine metacarpophalangeal joints with those of hyaluronic acid and chondroitin sulfate. Am. J. Vet. Res. 2010, 71, 399-404. [CrossRef] [PubMed]

16. Krylov, V.B.; Grachev, A.A.; Ustyuzhanina, N.E.; Ushakova, N.A.; Preobrazhenskaya, M.E.; Kozlova, N.I.; Portsel, M.N.; Konovalova, I.N.; Novikov, V.Y.; Siebert, H.C.; et al. Preliminary structural characterization, anti-inflammatory and anticoagulant activities of chondroitin sulfates from marine fish cartilage. Russ. Chem. Bull. 2011, 60, 746-753. [CrossRef]

17. Palhares, L.; Barbosa, J.S.; Scortecci, K.C.; Rocha, H.A.O.; Brito, A.S.; Chavante, S.F. In vitro antitumor and anti-angiogenic activities of a shrimp chondroitin sulfate. Int. J. Biol. Macromol. 2020, 162, 1153-1165. [CrossRef]

18. Han, J.; Guo, X.; Lei, Y.X.; Dennis, B.S.; Wu, S.X.; Wu, C.Y. Synthesis and characterization of selenium-chondroitin sulfate nanoparticles. Carbohyd. Polym. 2012, 90, 122-126. [CrossRef] [PubMed]

19. Zeng, S.Q.; Ke, Y.; Liu, Y.X.; Shen, Y.B.; Zhang, L.; Li, C.; Liu, A.P.; Shen, L.; Hua, X.J.; Wu, H.J.; et al. Synthesis and antidiabetic properties of chitosan-stabilized selenium nanoparticles. Colloid. Surface. B 2018, 170, 115-121. [CrossRef]

20. Liu, Y.T.; Zeng, S.Q.; Liu, Y.X.; Wu, W.J.; Shen, Y.B.; Zhang, L.; Li, C.; Liu, A.P.; Shen, L.; Hu, B.; et al. Synthesis and antidiabetic activity of selenium nanoparticles in the presence of polysaccharides from Catathelasma ventricosum. Int. J. Biol. Macromol. 2018, 114, 632-639. [CrossRef] 
21. TableYe, X.G.; Chen, Z.Z.; Zhang, Y.Y.; Mu, J.J.; Chen, L.Y.; Li, B.; Lin, X.R. Construction, characterization, and bioactive evaluation of nano-selenium stabilized by green tea nano-aggregates. LWT-Food Sci. Technol. 2020, 129, 109475.

22. Song, X.; Chen, Y.; Sun, H.; Liu, X.; Leng, X. Physicochemical stability and functional properties of selenium nanoparticles stabilized by chitosan, carrageenan, and gum Arabic. Carbohyd. Polym. 2021, 255, 117379. [CrossRef] [PubMed]

23. Gao, F.; Zhao, J.; Liu, P.; Ji, D.S.; Zhang, L.T.; Zhang, M.X.; Li, Y.Q.; Xiao, Y.L. Preparation and in vitro evaluation of multi-targetdirected selenium chondroitin sulfate nanoparticles in protecting against the Alzheimer's disease. Int. J. Biol. Macromol. 2020, 142, 265-276. [CrossRef]

24. Ding, L.; Huang, Y.; Cai, X.X.; Wang, S.Y. Impact of pH, Ionic Strength and Chitosan Charge Density on Chitosan/Casein Complexation and Phase Behavior. Carbohyd. Polym. 2019, 208, 133-141. [CrossRef]

25. Jiang, W.T.; Fu, Y.T.; Yang, F.; Yang, Y.F.; Liu, T.; Zheng, W.J.; Zeng, L.L.; Chen, T.F. Gracilaria lemaneiformis polysaccharide as integrin-targeting surface decorator of selenium nanoparticles to achieve enhanced anticancer efficacy. ACS Appl. Mater. Inter. 2014, 6, 13738-13748. [CrossRef]

26. Gao, X.; Li, X.F.; Mu, J.J.; Ho, C.T.; Su, J.Y.; Zhang, Y.T.; Lin, X.R.; Chen, Z.Z.; Li, B.; Xie, Y.Z. Preparation, Physicochemical Characterization, and Anti-Proliferation of Selenium Nanoparticles Stabilized by Polyporus Umbellatus Polysaccharide. Int. J. Biol. Macromol. 2020, 152, 605-615. [CrossRef] [PubMed]

27. Chen, W.; Yue, L.; Jiang, Q.; Liu, X.; Xia, W. Synthesis of varisized chitosan-selenium nanocomposites through heating treatment and evaluation of their antioxidant properties. Int. J. Biol. Macromol. 2018, 114, 751-758. [CrossRef] [PubMed]

28. Catarina Guedes, A.; Amaro, H.M.; Gião, M.S.; Xavier Malcata, F. Optimization of ABTS radical cation assay specifically for determination of antioxidant capacity of intracellular extracts of microalgae and cyanobacteria. Food Chem. 2013, 13, 638-643. [CrossRef] 